\title{
SIMULATION OF THE CARDIOVASCULAR SYSTEM USING EQUIVALENT ELECTRONIC SYSTEM
}

\author{
Kamran Hassani ${ }^{\mathrm{a}}$, Mahdi Navidbakhsh ${ }^{\mathrm{b}}$, Mostafa.Rostami ${ }^{\mathrm{c}}$
}

\author{
a Department of Biomedical Engineering, Amirkabir University of Technology, Tehran, Iran \\ e-mail:inspect@chagalesh.com \\ ${ }^{b}$ Department of Mechanical Engineering, Iran University of Science and Technology, Tehran \\ e-mail:m_navid@iust.ac.ir \\ c Department of Biomedical Engineering, Amirkabir University of Technology, Tehran \\ e-mail: rostami@aut.ac.ir
}

Received: April 10, 2006; Accepted: May 31, 2006

Key words: Model/Simulation/Electronic circuit/Cardiovascular System

This paper describes simulation of the cardiovascular system using a complex electronic circuit. In this study we have taken a slightly different approach to the modeling of the system and tried to advance existing electrical models by increasing more segments and parameters. The model consists of 42 segments representing the arterial system. Anatomical and physiological data for circuit parameters have been extracted from medical articles and textbooks. The frequency of heart is $1 \mathrm{~Hz}$ and the system operates in steady state condition. Each artery is modeled by one capacitor, resistor and inductor. The left and right ventricles are modeled using AC power suppliers and diodes. The results of the simulation including pressure and volume graphs exhibit operation of the cardiovascular system under normal condition. The results of the simulation have been compared with the relevant experimental observation and are in good agreement with them.

\section{INTRODUCTION}

Diseases of the human cardiovascular system are one of the main problems in contemporary health care in industrial countries. They cause the majority of deaths and also often afflict people in their most productive age. In this context different approaches were used with the aim of providing better understanding and simulation of the blood flow in the human cardiovascular system. A three parametric model of heart muscle mechanics was introduced ${ }^{1}$ and a modification of this model was presented later ${ }^{2}$. It successfully predicted force development during both isometric and isotonic contractions, showing deactivation of the contractile element during isotonic shortening and the apparent dependence of series stiffness in time. The study of the series elasticity of cardiac muscle was presented ${ }^{3}$. Afterwards, the time-varying elastance model of the left ventricle was introduced and later the relationship between pressure-volume area and cardiac oxygen consumption was described ${ }^{4}$. Finite element methods are commonly used to simulate the left ventricular performance. The first computer models describing the arterial system were presented in the sixties by some authors. They constructed a multi-branched model of the systemic arterial tree in a form usable for digital computer, which allowed simulation of different physiological and pathological conditions. This model was described in detail later ${ }^{5}$. Also blood flow through sites of particular interest of the arterial tree such as anastomo- ses, stenoses and bifurcations can be described with finite element method simulation. The mathematical description of the whole human cardiovascular system remains a complex task and for that reason models are simplified with respect to particular parts of interest are presented. A pulsatile-flow model of the left heart and two-segment aorta was constructed and the changes in flow work investigated, time-tension index and stroke volume produced by an intra aortic balloon pump. Later an open-loop lumpedparameter model was developed and the sensitivity of an intra aortic balloon pump to timing, rate of inflation, balloon placement and stroke volume was determined ${ }^{6}$. The model later yielded good results for a short-term interaction between the assist device and the circulation ${ }^{7}$. The model of an assisted failing canine circulation was presented from which cardiac oxygen supply and consumption could be calculated ${ }^{8}$. The influence of drugs on the circulation was studied later in a 19-compartment model also the use of computer-aided design of control systems was improved to produce a simple electrical analog of the human cardiovascular system and used to simulate steadystate circulatory conditions with transients introduced by varying the peripheral resistance ${ }^{9}$. A non-linear computer model for pressure and flow propagation in the human arterial system was developed ${ }^{10}$. The model with 55 arterial segments is based on one-dimensional flow equation and simulates different homodynamic effects on blood flow. The simulation of steady state and transient phenomena using the electronic circuit has also been done but the 
arteries have not been included in their model widely ${ }^{11}$. The model which is presented here describes simulation of the cardiovascular system using a complex electronic circuit. In this study, we have taken a slightly different approach to the modeling of the system. We have tried to advance existing electrical models by increasing more segments and parameters. Compared to previous studies, the arterial system of this model is more detailed. Therefore, normal and abnormal performance of arterial system can be studied.

\section{MODEL SIMULATION PRINCIPLES}

The block diagram of cardiovascular system is shown in Fig. 1. This diagram is an actual presentation of physiological cardiovascular and arterial system ${ }^{12}$. In our model, every blood, vessel, atrium, ventricle and set of all capillaries and arterioles have been presented by a block consisting of a resistor, an inducer and a capacitor. Voltage, current, charge, resistance and capacitance in the electronic circuit are equivalent to blood pressure, flow, volume, resistance and compliance in the cardiovascular system. Ground potential (reference for voltage measurements) is equivalent to zero. The correlation between electrical characteristics of the system and their mechanical counterparts are as follow:

$1 \mathrm{mmHg}=1$ volt $($ pressure $\sim$ voltage $)$

$1 \mathrm{ml}=10 \mu$ As (volume $\sim$ charge)

$0.01 \mathrm{ml} / \mathrm{Pa}=1 \mu \mathrm{F}$ (compliance $\sim$ capacitance $)$

$1 \mathrm{~Pa} . \mathrm{s} / \mathrm{ml}=1 \mathrm{k} \Omega$ (resistance)

$1 \mathrm{~Pa} . \mathrm{s}^{2} / \mathrm{ml}=1 \mu \mathrm{H}$ (inertia $\sim$ inducer $)$

$1 \mathrm{~s}=1 \mathrm{~s}$ (unit of time)

Blood vessels resistance, depending on blood viscosity and vessel diameter, is simulated by resistors. The vessel compliance is simulated by capacitors. The blood inertia is considered using inducers. Atriums are simulated as part of the venous system without any contraction. Atriums are modeled as a resistor-capacitor segment. Ventricles are simulated as a section of blood vessels in which its resting capacitance (diastole) can be decreased (systole) and then returned to the resting capacitance. Essentially, energy of systolic contraction of left and right ventricles is modeled by superposition of three AC power supplies and diodes. These voltage sources are amplifiers and the inputs of them are connected to the capacitors simulating atriums. Thus, during systole, the voltage from the ventricular capacitor is amplified and applied to the aortic capacitor. The specification of each block is explained in Table 1. As can be seen, each block consists of a resistor $(\mathrm{R})$, an inducer (L) and a capacitor (C).

\section{SYSTEM DESCRIPTION}

The equivalent circuit of the cardiovascular system is shown in Fig. 2. In this simulation, blood volume, cardiac output and aortic pressure should be $5000 \mathrm{ml}, 83 \mathrm{ml} / \mathrm{s}$ and $80-120 \mathrm{mmHg}$. To facilitate the understanding of the circuit, the anatomic structures are brought into it.

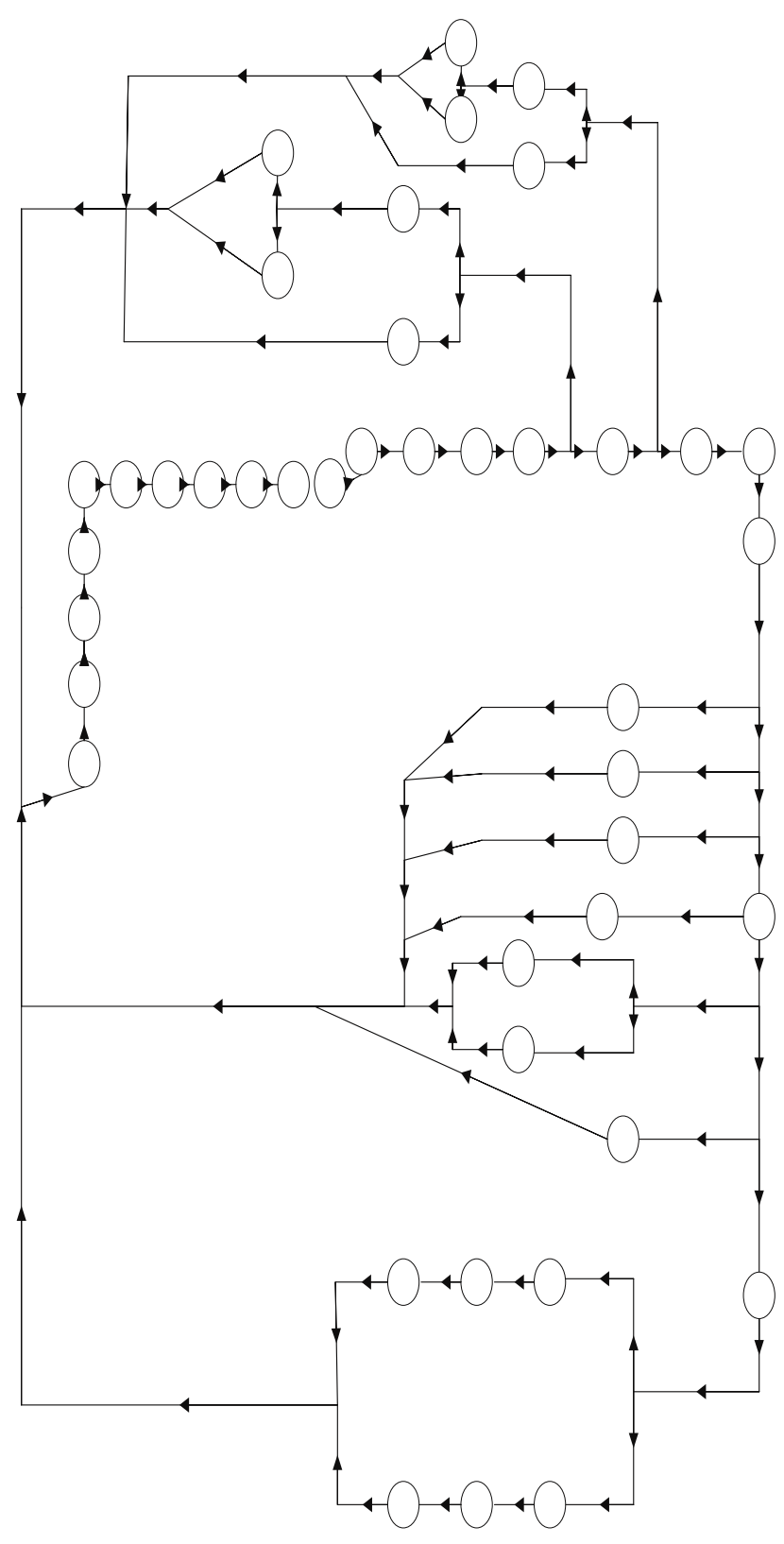

Fig. 1. Block diagram of the cardiovascular system: 1-Left Atrium; 2-Left Ventricle; 3, 4, 5, 12, 13, 14, 15, 16- different Aorta Sections; 6 to 11 , A, B-Carotid and Subclavin Arteries; 17 to 22Femoral and Iliac Arteries sections; 23-Hepatic; 24-Gastric; 25-Splentic;26-Left Renal;27-Right Renal; 28-Superior Mesenteric; 29-Inferior Mesenteric; 30-Arterioles; 31-Capillaries; 32 and 33- Veins; 34-Right Atrium; 35-Right Ventricle; C, D, E-Pulmonary Artery Sections; F,G-Pulmonary Veins. For detailed specification of each component Table. 1 shall be seen.

Similarly as the preparation in vivo, also the equivalent circuit can be subdivided into two parts: heart (atrium and ventricle) and the arterial circulation. The left atrium and ventricle are represented by two capacitors $101 \mu \mathrm{F}$ and $25 \mu \mathrm{F}$. Also right atrium and ventricle are modeled by two capacitors $216.45 \mu \mathrm{F}$ and $150 \mu \mathrm{F}$. Using of suitable 


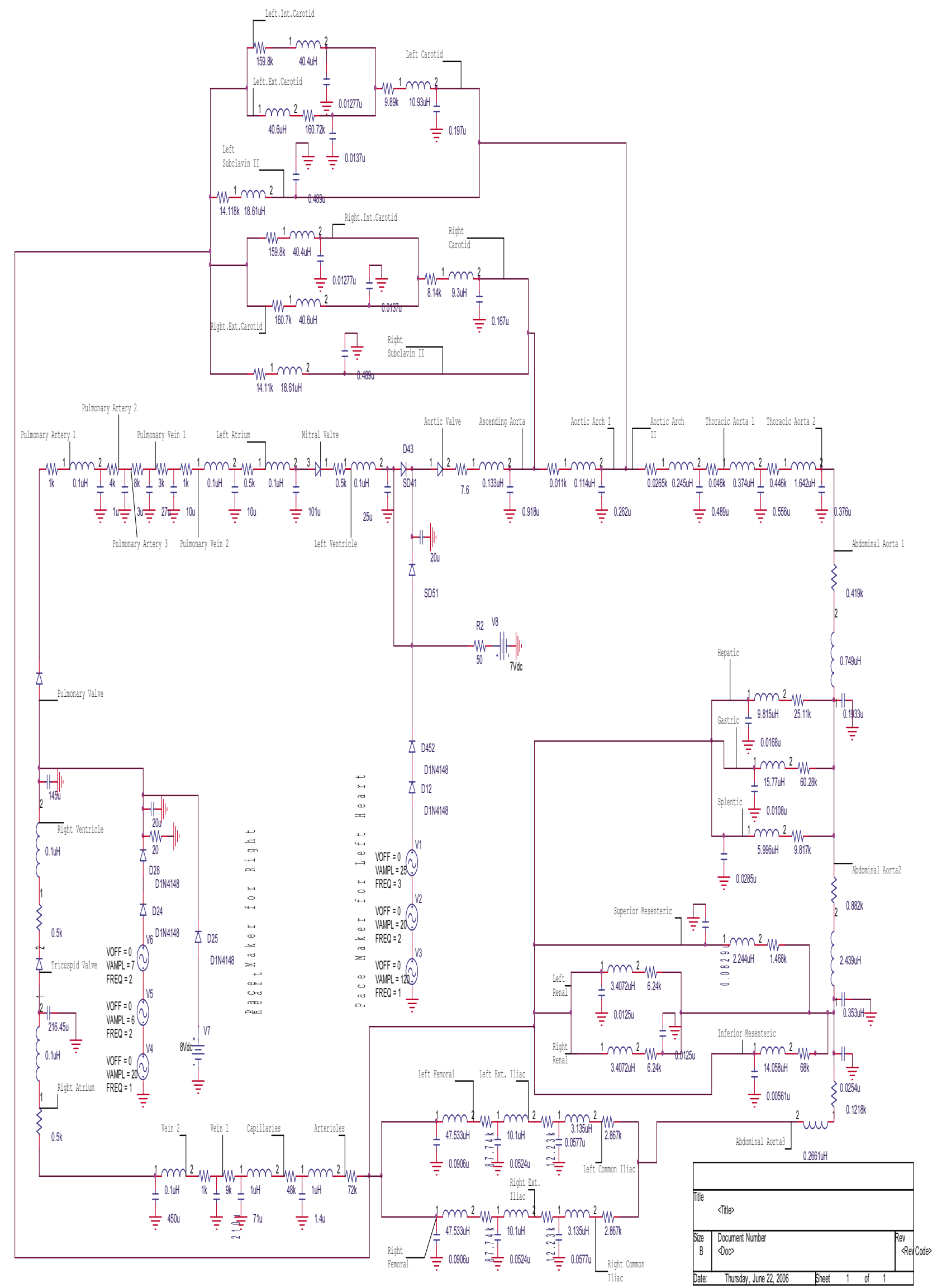

Fig. 2. Electronic circuit of cardiovascular system. 
** Profile: "SCHEMATIC1-wery" [ C: Program Files\orcad\cardiovascular-SCHEMATIC1-wery.sim ]

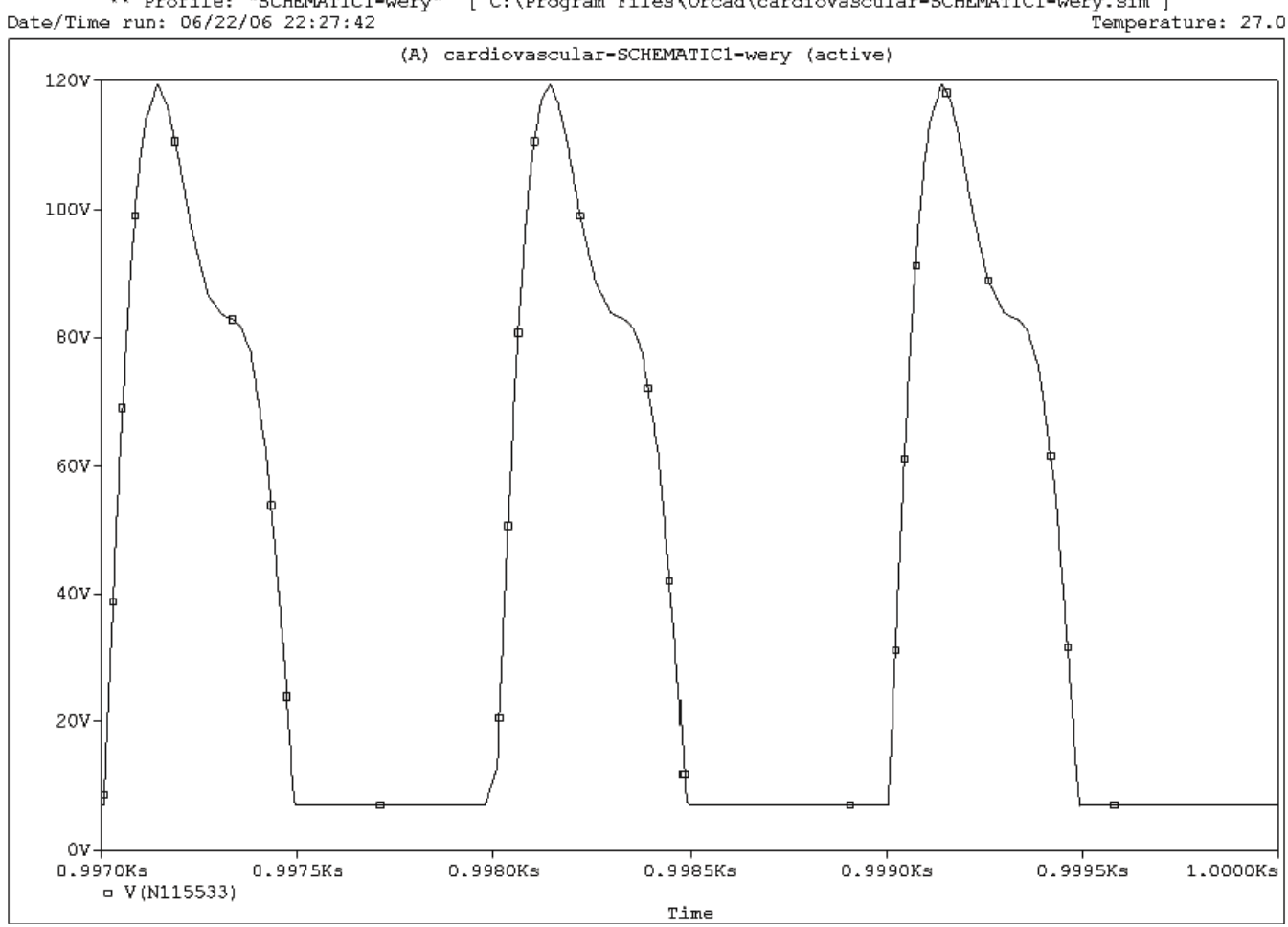

Fig. 3. Pressure graph of left ventricle for frequency of $1 \mathrm{~Hz}$.

** Profile: "SCHEMATIC1-ert" [ C: Program Files\Orcad DatefTime rup: 06/23/06 18:36:26

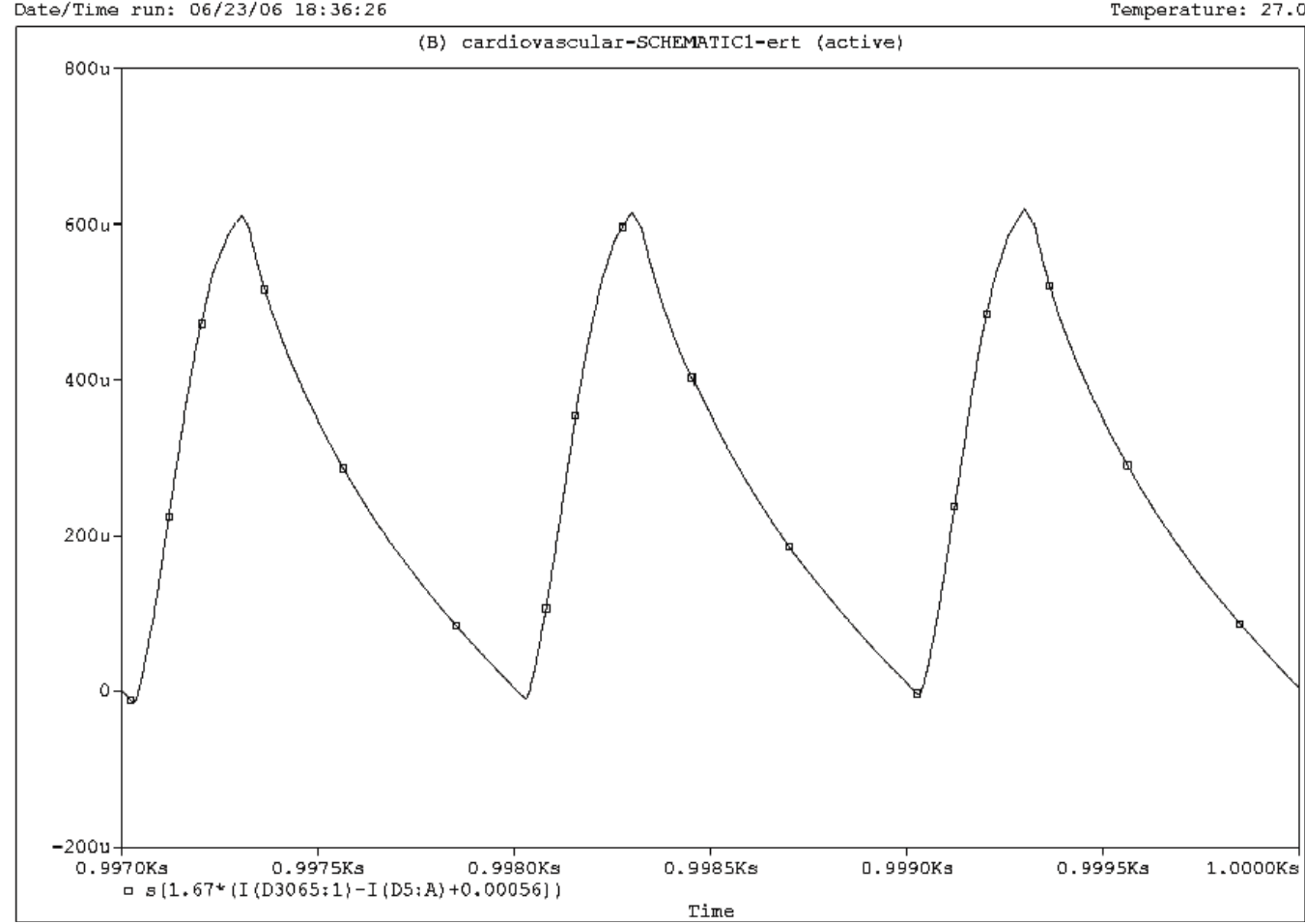

Fig. 4. Volume graph of left ventricle for frequency of $1 \mathrm{~Hz}$. 
** Profile: "SCHEMATIC1-wery" [ C: \Program Files\orcad\cardiovascular-SCHEMATIC1-wery.sim ]

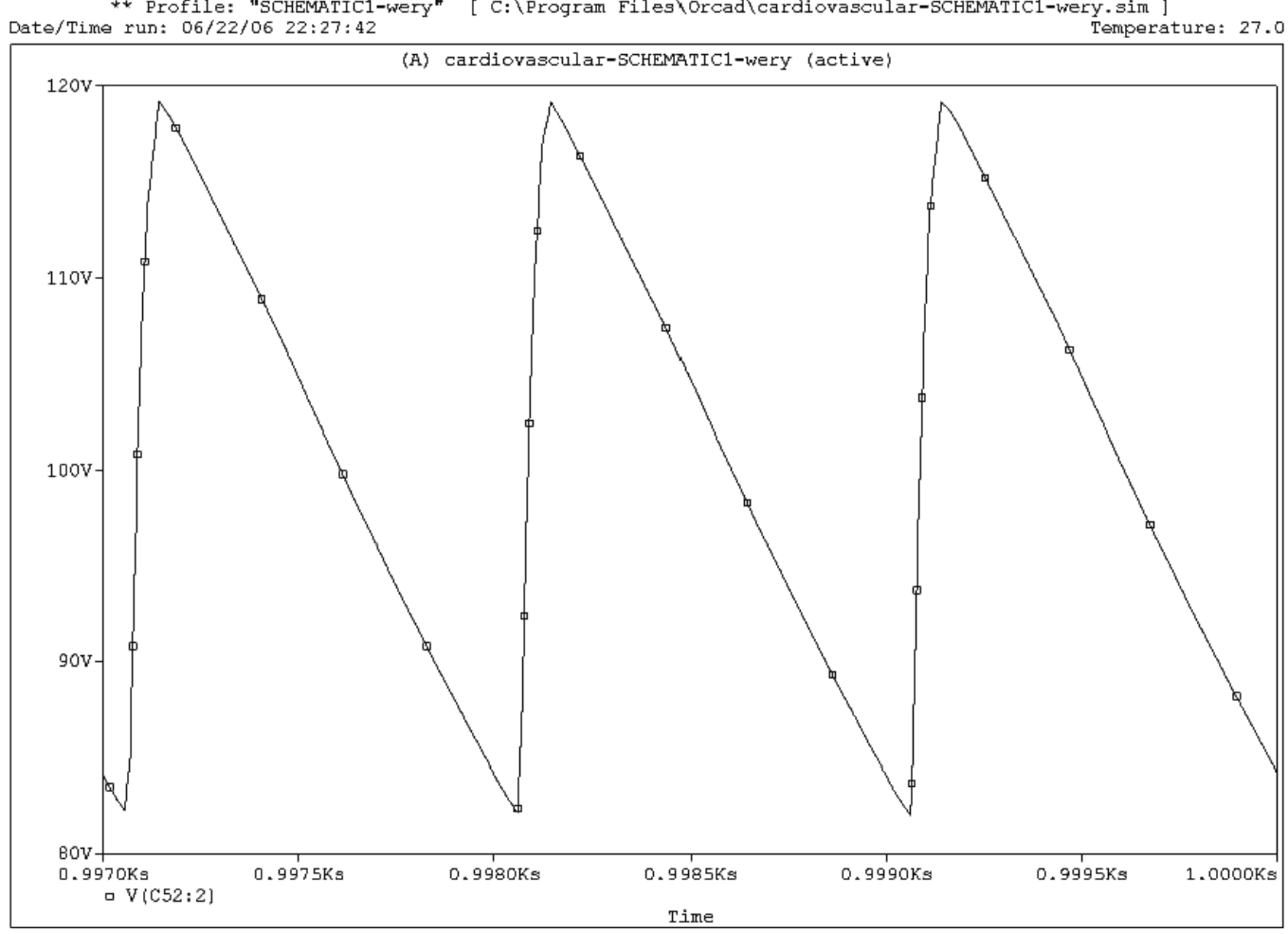

Fig. 5. Pressure graph of Aorta for frequency of $1 \mathrm{~Hz}$.

** Profile: "SCHEMATIC1-wery" [ C: \Program Filesłorcadไcardiovascular-sCHEMATIC1-wery.sim ]

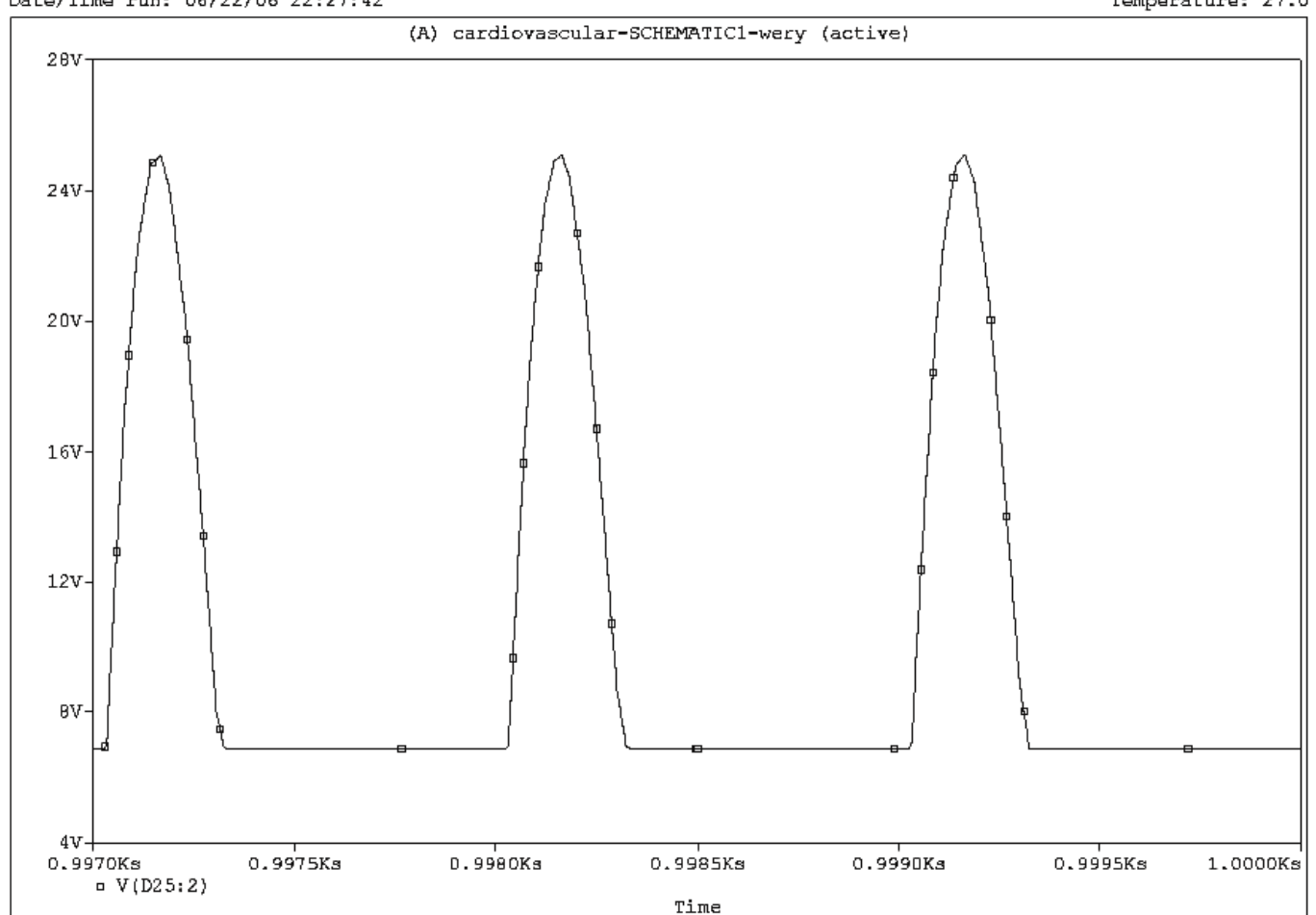

Fig. 6. Pressure graph of right ventricle for frequency of $1 \mathrm{~Hz}$. 


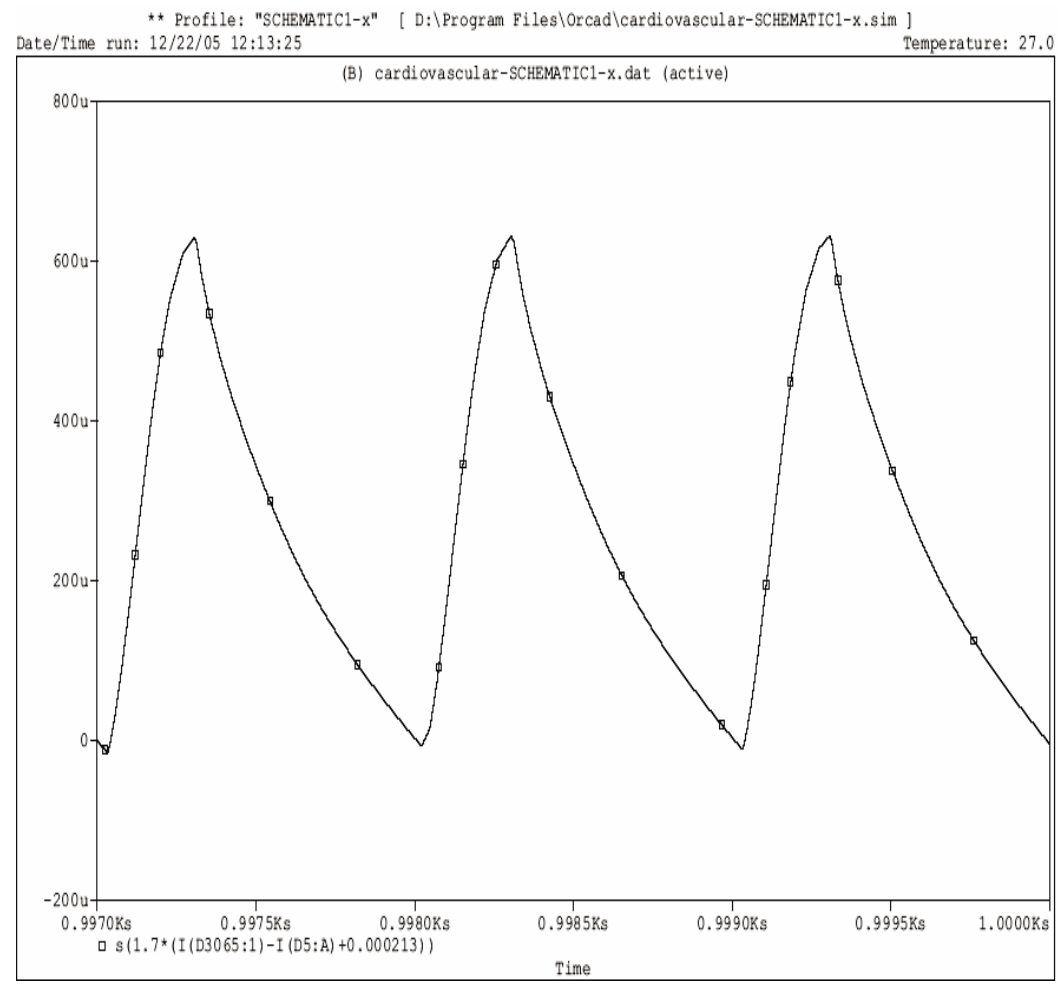

Fig. 7. Volume graph of right ventricle for frequency of $1 \mathrm{~Hz}$.

diodes was very important matter in this circuit. The aortic, mitral, tricuspid and pulmonary valve are simulated with ideal diodes: SD41, SD41, 120NQ045 and QSCHSS45/-55. Using these types of diodes have helped the circuit to show the operation of the cardiovascular system properly.

The contracting-relaxing actions of the left and right ventricles are achieved by the pacemaker. The pace maker consists of three AC power supply and two diodes (DIN4148). The pacemaker has the pulse generator of $1 \mathrm{~Hz}$. For each ventricle, one pace maker is used in order to drive the voltage into the circuit. As it can be seen in the Fig. 2, a 8 DC voltage source is used for the right ventricle pacemaker to help the pressure graph of the ventricle to vary between 8 to 25 volt $(\mathrm{mmHg})$ as another $7 \mathrm{DC}$ source is used for left ventricle to adjust variation of pressure between 7-120 volt ( $\mathrm{mmHg}$ ) for it. The values of R.L and $\mathrm{C}$ were either directly extracted from references ${ }^{8,9}$ or were calculated using formulas of reference ${ }^{10}$. The circuit consists of the biggest arteries and arterioles have been simulated as one separated compartment with resistance of $72 \mathrm{k} \Omega$ and capacitance of $1.4 \mu \mathrm{F}$. The capillaries and veins are also modeled by one and two segments. The upper body arteries such as carotid have been attached to arterioles by one connection. The generated current of suppliers distribute to left ventricle, aorta and upper body arteries. It continues its path toward the body arteries such as femoral, renal or gastric. The current passes the arterioles, capillaries and veins and enters to right atrium. Another amplifier, pacemaker, generates the required current for circulation in the pulmonary arteries and veins and the final current enters the left atrium finally. One of the major problems of these types of complex circuits is stability. The stability of the circuit was checked by running it for long periods of time (1000 s to $5000 \mathrm{~s})$ and no sign of instability was observed. All of the current and voltage graphs have been checked for oscillating and there is no sign of oscillation in these graphs. The model is capable of showing pressure and volume signals for different arteries throughout carotid to femoral triggered by initial systolic contraction. The pressure (voltage) graphs can be obtained from the different points of the circuit easily but volume graphs cannot be obtained directly meaning that integration of current - time graph shall be obtained as charge-time graph for each element. It shall be noted that there is no leakage of charge in the system and the output voltage is proportional to the input voltage. The proportionality factor reflects the contractility of the ventricles. To meet this end both terminals of ventricles capacitors are connected to the pace makers connections. Due to their high input impedance, there is no appreciable leakage of charge from the circuit. In this circuit there is no point of constant pressure (voltage). Therefore, total capacitance of the system $(905 \mu \mathrm{F})$ is one of the important determinants of its functions. The ratios of capacitances determine the distribution of total charge in the circuit. The ratio between total systemic arterial and systemic venous capacitance is about 0.01 . The ratio between total systemic and pulmonary is 0.15 . These ratios are similar to those reported for the human cardiovascular system ${ }^{13,14}$. 
Table 1. The specifications of the model segments

\begin{tabular}{|c|c|c|c|c|}
\hline ITEM & DESCRIPTION & $\mathrm{R}(\mathrm{k} \Omega)$ & $L(\mu \mathrm{H})$ & $C(\mu F)$ \\
\hline 1 & Left Atrium & 0.5 & 0.1 & 101 \\
\hline 2 & Left Ventricle & 0.5 & 0.1 & 25 \\
\hline 3 & Ascending Aorta & 7.6 & 0.133 & 0.918 \\
\hline 4 & Aortic Arch 1 & 0.011 & 0.144 & 0.262 \\
\hline 5 & Aortic Arch 2 & 0.0265 & 0.245 & 0.489 \\
\hline 6 & Right Subclavin II & 14.118 & 18.61 & 0.489 \\
\hline 7 & Right C ar otid & 8.14 & 9.3 & 0.167 \\
\hline 8 & Right. int.Car otid & 159.8 & 40.4 & 0.01277 \\
\hline 9 & Right. ext.Carotid & 160.7 & 40.6 & 0.0137 \\
\hline 10 & Left Subclavin II & 14.118 & 18.61 & 0.489 \\
\hline 11 & Left C arotid & 9.89 & 10.93 & 0.197 \\
\hline $\mathrm{A}$ & Left.int.Carotid & 159.8 & 40.4 & 0.01277 \\
\hline $\mathrm{B}$ & Left.ext.Carotid & 160.72 & 40.6 & 0.0137 \\
\hline 12 & Thor acic Aorta 1 & 0.046 & 0.374 & 0.556 \\
\hline 13 & Thoracic A orta 2 & 0.446 & 1.642 & 0.376 \\
\hline 14 & Abdominal Aorta 1 & 0.419 & 0.749 & 0.1933 \\
\hline 15 & Abdominal Aorta 2 & 0.882 & 2.439 & 0.353 \\
\hline 16 & Abdominal Aorta 3 & 0.1218 & 0.2661 & 0.0254 \\
\hline 17 & Left Com mon Iliac & 2.867 & 3.135 & 0.0557 \\
\hline 18 & Left External Iliac & 12.23 & 10.1 & 0.0524 \\
\hline 19 & Left Femoral & 87.74 & 47.533 & 0.0906 \\
\hline 20 & Right Common Iliac & 2.867 & 3.135 & 0.0577 \\
\hline 21 & Right External Iliac & 12.23 & 10.1 & 0.0524 \\
\hline 22 & Right F emoral & 87.74 & 47.533 & 0.0906 \\
\hline 23 & Hepatic & 25.11 & 9.815 & 0.0168 \\
\hline 24 & Gastric & 60.28 & 15.77 & 0.0108 \\
\hline 25 & Splenic & 9.817 & 5.996 & 0.0285 \\
\hline 26 & Left Renal & 6.24 & 3.4072 & 0.0125 \\
\hline 27 & Right Renal & 6.24 & 3.4072 & 0.0125 \\
\hline 28 & Superior Mesenteric & 1.468 & 2.244 & 0.0829 \\
\hline 29 & Inferior Mesenteric & 68 & 14.058 & 0.00561 \\
\hline 30 & Arterioles & 72 & 1 & 1.4 \\
\hline 31 & Capillaries & 48 & 1 & 71 \\
\hline 32 & Vein 1 & 9 & - & 210 \\
\hline 33 & Vein 2 & 1 & 0.1 & 450 \\
\hline 34 & Right Atrium & 0.5 & 0.1 & 216.45 \\
\hline 35 & Right $V$ entricle & 0.5 & 0.1 & 150 \\
\hline $\mathrm{C}$ & Pulmonary Artery 1 & 1 & 0.1 & 1 \\
\hline $\mathrm{D}$ & Pulmonary Artery 2 & 4 & - & 1 \\
\hline $\mathrm{E}$ & Pulmonary Artery 3 & 8 & - & 3 \\
\hline F & Pulmonary $\mathrm{V}$ ein 1 & 3 & - & 27 \\
\hline $\mathrm{G}$ & Pulmonary $\mathrm{V}$ ein 2 & 1 & 0.1 & 10 \\
\hline
\end{tabular}

\section{RESULTS}

The results of the simulation performed for a heart rate of 60 beats per minute $(1 \mathrm{~Hz})$ are given in Fig. 3 to Fig. 7. The pressure-time graph of left ventricle is shown in Fig. 3, where the waveform varies between 7-120 mmHg (volt). The results are in complete agreement with experimental observation of physiological Text ${ }^{11}$. The waveform starts from $7 \mathrm{mmHg}$ and the peak is in $120 \mathrm{mmHg}$. Please note that each cycle is $1 \mathrm{~s}$ according to in vivo condition of 60 beats per minute. Also, the volume graph of left ventricle which is shown in Fig. 4, indicates the difference of $600 \mu$ As $(60 \mathrm{ml})$ between systole and diastole. The experimental data of physiological reference ${ }^{15,2}$ confirm it. In cardiovascular system, the volume graph of left ventricle varies between $60-120 \mathrm{ml}$ but regarding the nature of the model, volume graph of Fig. 4 varies between 0-60 ml. This can be interpreted by keeping the $60 \mathrm{ml}$ difference. The effort was to keep the $60 \mathrm{ml}$ difference of systole and diastole according to Fig. 4.
The pressure changes of aorta artery are shown in Fig. 5. This graph shows that aorta pressure varies between 80-120 mmHg (diastole-systole) and the results are in agreement with physiological article ${ }^{16}$.

Fig. 6 shows the pressure graph of right ventricle varying between 8-25 mmHg. The actual graph of right ventricle confirms this simulation result in accordance with physiological data of reference ${ }^{17}$.

Also, The volume graph of right ventricle is shown in Fig. 7. According to what explained for volume graph of left ventricle, this graph varies between $0-600 \mu$ As or 0-60 ml. Note that volume variation of both ventricles are the same.

This volume is in good agreement with physiological data of reference ${ }^{15,2}$. In the equivalent circuit cardiac output can be strongly increased by increasing the value of both capacitors simulating right and left ventricle, it should be remembered that in the same time the value of both corresponding resistors should be decreased to keep the same time constant for contraction and relaxation, re- 
spectively, of the heart. If contraction of atria is required, both atriums can be simulated as low-pressure pumps. Its simulation circuit should be the same as that for the ventricle, however because of the four pumps connected in series the circuit would be extremely complex.

In this model, for didactic reasons, the right and left ventricles are not identical. The values of resistors and capacitances are not the same value but the resemblances to conditions in vivo are improved. All of valves have been simulated by diodes and a very small, so-called physiologic back flow of blood occurs. However, this back flow is negligible compared with cardiac output. Using the circuit, it is possible to simulate heart valves by switches driven by voltage and no back flow is observed but the circuit will be complex and likely unstable. It seems that use of this equivalent electronic circuit of cardiovascular system is useful for studying of whole cardiovascular system and is a useful tool in teaching physiology and pathophysiology for students. Also different cardiovascular pathologies such as arterial aneurysms or cardiac abnormities can be studied with changing model's parameters.

\section{REFERENCES}

1. Zacek M, and Krause E. (1996) Numerical simulation of the blood flow in the human cardiovascular system. Journal of biomechanics $32,13-20$

2. Rideout VC, Mathematical and computer modeling of physiological systems. New York: Prentice Hall, 1991.

3. Rupnic M, and Runvovc F. (2002) Simulation of steady state and transient phenomena by using the equivalent electronic circuit. Journal of Computer methods and programs in biomedici 67, $1-12$.

4. T.Helde,t and E.Shim. (2002) Modeling of cardiovascular response to orthostatic stress. Journal of applied physiology 92, 1239-54.
5. Wang JJ, and Parker KH. (2004) Wave propagation in a model of the arterial circulation. Journal of biomechanics 37, 457-70.

6. Migliaavacca F, and Cellier GE. (2001) Modeling of the Norwood circulation: effects of shunt size, vascular resistance and heart. Journal of phisiol. Heart circ .phisiol 280, 457-70.

7. Nebot A, Cellier FE, and Vallverdu M. (1988) Mixed quantitive/ qualitive modeling of the cardiovascular system and simulation of it. Journal of computer methods and programs in biomedicine 55 , 127-55.

8. Mukkamala R, and Cotton RJ. (2001) A forward model-based validation of cardiovascular system identification. Journal of phisiol heart circ phisiol 281, 2714-30.

9. Nardinochini P, Pontrelli G, and Teresi L. (2005) A one-dimensional model for blood flow in pre stressed vessel. European Journal of Mechanics 24, 23-33.

10. Torii R, Oshima M, and Kobayashi T. (2005) Computer modeling of cardiovascular fluid-structure interactions with the deformingspatial-domain-time formulation. Computer methods in Applied Mechanics and Engineering 13, 549-57.

11. Guyton AC, Text book of physiology, vol. I. Philadelphia: W.B.Saunders, 1996.

12. Korakianitis T, and Shi Y. (2001) Numerical simulation of cardiovascular dynamics with healthy and diseased heart valves. Journal ofapplied physiology 15, 549-57.

13. Pralhad RN, and Shultz DH. (2004) Modeling of arterial stenosis and its applications to blood diseases. Journal of Mathematical Biosciences 190, 203-20.

14. Smith BW, Chase JG, and Wake G. (2004) Minimal haemodynamic system model including ventricular interaction and valve dynamics. Journal of Medical Engineering and Physics 26, 131-39.

15. Steinman DA, Vorp DA, and Ethier CR. (2003) Computational modeling of arterial biomechanics: insight into pathogenesis and treatment of vascular disease. Journal of Vascular Surgery 37, 1118-28.

16. Podnar T, Runovc F, and Kordag M. (2002) Simulation of cardiovascular physiology: the diastolic functions of the heart. Journal of Computers in Biology and Medicine 32, 363-77.

17. Ansari M, Alexander M, and Massie BM. (2003) Cardiology participation improves outcomes in patients with new-onset heart failure in the outpatient setting. Journal of the American College of Cardiology 41, 62-8. 